\title{
Rapid Quantification of Topotecan in Biological Samples by Liquid Chromatography/Tandem Mass Spectrometry
}

\author{
Beom Soo Shin ${ }^{1}$, Mann Hyung Lee ${ }^{1}$ and Sun Dong Yoo $^{2 \uparrow}$ \\ ${ }^{1}$ College of Pharmacy, Catholic University of Daegu, Gyeongsan-si, Gyeongbuk, Korea \\ ${ }^{2}$ College of Pharmacy, Sungkyunkwan University, Suwon, Gyeonggi-do, Korea \\ (Received September 28, $2009 \cdot$ Revised October 4, $2009 \cdot$ Accepted October 7, 2009)
}

\begin{abstract}
A rapid liquid chromatography/tandem mass spectrometry (LC/MS/MS) assay method was developed for the determination of topotecan levels in rat serum. The assay utilized a single liquid-liquid extraction with a mixture of ethyl acetate and acetonitrile $(6: 1 \mathrm{v} / \mathrm{v})$ and isocratic elution. The multiple reaction monitoring was based on the transition of $\mathrm{m} /$ z $422.0 \rightarrow 376.5$ for topotecan and $315.1 \rightarrow 226.6$ for clomipramine (internal standard). The developed assay was validated to demonstrate the specificity, recovery, lower limit of quantification (LLOQ), accuracy and precision. The assay was linear over a concentration range from $0.5-100 \mathrm{ng} / \mathrm{mL}$, with LLOQ being $0.5 \mathrm{ng} / \mathrm{mL}$ using a small volume of rat serum $(0.1 \mathrm{~mL})$. The mean intra- and inter-day assay accuracy was $87.7-111.0 \%$ and $97.8-108.3$, respectively, and the mean intra- and interday precision was between $1.6-4.3 \%$ and $3.8-10.3$, respectively. The developed assay was applied to a pharmacokinetic study after a bolus i.v. injection of topotecan in rats.
\end{abstract}

Key words - Topotecan, LC/MS/MS, Clomipramine, Pharmacokinetics

Topotecan is an analog of camptothecin and is classified as a topoisomerase I inhibitor. Topoisomerase I inhibitors break the single-strand DNA and terminate the DNA replication, leading to cell death. ${ }^{1-4)}$ Compared with camptothecin, topotecan is more water soluble, less toxic and exhibits higher selectivity in solid tumors. ${ }^{5)}$ Topotecan shows the antitumor activity in several tumor models. ${ }^{6.7)}$ It is commercially available under a trade name Hycamtin for the treatment of ovarian and lung cancers. Recent clinical phase I studies have shown that i.p. chemotherapy is also effective for the treatment of metastatic peritoneal cancers. ${ }^{89}$ ) Topotecan undergoes $\mathrm{pH}$ dependent, reversible conversion between lactone and carboxylate forms. The lactone form is known to possess higher topoisomerase activity than the carboxylate form. ${ }^{10)}$ The lactone form may be more easily influenced by the route of administration and the biological $\mathrm{pH}^{11)}$ The systemically administered topotecan is eliminated mainly by the liver and kidney, with $60-70 \%$ excreted in urine as unchanged drug in children. ${ }^{11)}$ Topotecan is known to be a substrate of the ATPbinding cassette transporter. A number of pharmacokinetic studies have been conducted to relate the topotecan pharmacokinetics with the action of transporters. ${ }^{12-16)}$ To date, a number of high-performance liquid chromatographic assay

†본 논문에 관한 문의는 이 저자에게로

Tel : 02)290-7717, E-mail : sdyoo@skku.ac.kr

DOI : 10.4333/KPS.2009.39.5.367 methods are available for the quantification of topotecan in biological samples utilizing liquid-liquid extraction ${ }^{17-19)}$ and protein precipitation. ${ }^{20}$ ) These assays, however, require relatively long chromatographic running times. The present study for the first time reports a rapid and sensitive LC/MS/MS assay method for the quantification of topotecan in rat serum. The developed assay was utilized in a pharmacokinetic study in rats after i.v. injection.

\section{Materials and Methods}

\section{Chemicals}

Topotecan hydrochloride was purchased from Geneary (Shanghai, China), and clomipramine hydrochloride (internal standard), formic acid and phosphoric acid were purchased from Sigma (St. Louis, MO, USA). Potassium monophosphate and potassium diphosphate were obtained from Aldrich (Milwaukee, WI, USA). HPLC grade acetonitrile, methanol and ethyl acetate were purchased from J.T. Baker (Phillipsburg, NJ, USA). Water was de-ionized prior to use using a Millipore Milli-Q water purification system (Milford, MA, USA).

\section{Preparation of Standard and Quality Control Samples}

The stock solutions of topotecan and clomipramine (internal standard) were prepared by separately dissolving $10 \mathrm{mg}$ each in $100 \mathrm{~mL}$ of methanol. The standard working solutions of topotecan were prepared by serial dilution with methanol, 
yielding concentrations of $1000,500,100,50,10$ and $5 \mathrm{ng} / \mathrm{mL}$. The standard calibrator solution was prepared by spiking the standard working solutions ( $10 \mu \mathrm{L}$ each) to blank rat serum $(90 \mu \mathrm{L})$, yielding drug concentrations of 100, 50,10, 5, 1 and $0.5 \mathrm{ng} / \mathrm{mL}$. The internal standard working solution was prepared by dilution with methanol, yielding a concentration of $250 \mathrm{ng} / \mathrm{mL}$. The quality control (QC) samples were prepared by spiking the working drug solutions to blank rat serum to provide high concentration $\mathrm{QC}(80 \mathrm{ng} / \mathrm{mL})$, medium concentration QC (20 ng/mL), low concentration QC $(8 \mathrm{ng} / \mathrm{mL})$, and lower limit of quantification (LLOQ) QC $(0.5 \mathrm{ng} / \mathrm{mL})$. Each QC sample was prepared once, and aliquots $(100 \mu \mathrm{L})$ were placed in borosilicate glass tubes. QC samples, stock and standard working solutions were stored at $-20^{\circ} \mathrm{C}$.

\section{Sample Extraction}

To rat serum $(100 \mu \mathrm{L}), 100 \mu \mathrm{L}$ of formic acid $(0.5 \%)$ was added for conversion of carboxylate form to lactone form. One hour later, the internal standard working solution $(10 \mu \mathrm{L}$, clomipramine $250 \mathrm{ng} / \mathrm{mL}$ in methanol) and the mixture of ethyl acetate and acetonitrile $(6: 1, \mathrm{v} / \mathrm{v})(3.5 \mathrm{~mL})$ were added and vortex-mixed for $10 \mathrm{~min}$. The upper organic layer was transferred to a test tube and evaporated on a heating block (Dry Thermobath MG-2100, Tokyo Rikakikai, Tokyo, Japan) at $40^{\circ} \mathrm{C}$ under $\mathrm{N}_{2}$. The residue was reconstituted with the mobile phase $(300 \mu \mathrm{L})$ on the vortex mixer for $10 \mathrm{~min}$ and a portion $(20 \mu \mathrm{L})$ was injected into LC/MS/MS.

\section{Instrumentation and LC/MS/MS Conditions}

HPLC was performed by a Shimadzu 10Avp system (Kyoto, Japan) consisting of SCL-10Avp system controller, LC10ADvp pump, SIL-10Avp auto sampler, CTO-10Avp column oven and DGU-14A degasser. Compounds were separated on a Gemini $\mathrm{C}_{18}$ column $(150 \times 2.1 \mathrm{~mm}$ i.d., $5 \mu \mathrm{m})$ with a Security Guard column $(4 \times 2 \mathrm{~mm}$ i.d.) (Phenomenex, Torrance, CA, USA). The mobile phase consisted of acetonitrile and deionized water containing formic acid $(0.1 \%)$ at a ratio of 80:20 (v/ $\mathrm{v})$. The flow rate of the mobile phase and the column oven temperature were set at $0.2 \mathrm{~mL} / \mathrm{min}$ and $40^{\circ} \mathrm{C}$, respectively. The HPLC system was coupled to an API 2000 triple-quadrupole mass spectrometer equipped with a turbo ion spray ionization source (AB MDS Sciex, Toronto, Canada). The turbo ion spray ionization source was operated in a positive mode. The curtain, nebulizer, and turbo gas (nitrogen) were set at 25,60 , and $60 \mathrm{psi}$, respectively. The turbo gas temperature was $400^{\circ} \mathrm{C}$. The mass spectrometer was operated at a unit resolution for both Q1 and Q3 in the multiple reaction monitoring (MRM) mode with a dwell time of $300 \mathrm{~ms}$ in each transition.
The transition of the precursor to the product ion was monitored at $422.0 \rightarrow 376.5$ for topotecan and $315.1 \rightarrow 226.6$ for clomipramine. The collision energy was set at 27 and $57 \mathrm{eV}$ for topotecan and clomipramine, respectively. Data acquisition was preformed with the Analyst 1.4 software (AB MSD Sciex, Toronto, Canada).

\section{Calibration}

Calibration curves ranging from $0.5-100 \mathrm{ng} / \mathrm{mL}$ were prepared by spiking the blank rat serum $(100 \mu \mathrm{L})$ at concentrations of $0.5,1,5,10,50$ and $100 \mathrm{ng} / \mathrm{mL}$. The calibration curves were constructed by the weighted regression method (1/ $\mathrm{x})$ of peak area ratios of topotecan to internal standard vs. actual concentration. The lower limit of quantification (LLOQ) was defined as the lowest serum topotecan concentration that yielded a $\mathrm{S} / \mathrm{N}$ ratio $>10$, with acceptable accuracy and precision $(<15 \%)$. The precision was expressed as the coefficient of variation $(\% \mathrm{CV})$ at each concentration, and the accuracy was expressed as the percentage of mean calculated vs. actual concentrations. Intra- and inter-day assay variability of topotecan was determined by assaying LLOQ $(0.5 \mathrm{ng} / \mathrm{mL})$, low $(8$ $\mathrm{ng} / \mathrm{mL})$, medium $(20 \mathrm{ng} / \mathrm{mL})$ and high $\mathrm{QC}(80 \mathrm{ng} / \mathrm{mL})$ samples on 3 consecutive days with 3 replicate samples each day, respectively.

\section{Stability}

The stability of topotecan was examined under 3 different conditions described below using 3 replicates of low and high QC samples. To assess the topotecan stability in rat serum at room temperature (RT), low and high rat serum QC samples left at RT for $6 \mathrm{hr}$ were analyzed. To assess the auto sampler stability, extracted low and high QC samples of topotecan dissolved in the mobile phase left in the auto sampler rack at RT for $24 \mathrm{~h}$ were compared with the immediate work-up concentrations. To assess the freeze-thaw stability, serum samples spiked with topotecan at 8 and $80 \mathrm{ng} / \mathrm{mL}$ stored at $-20^{\circ} \mathrm{C}$ were subject to 3 freeze-thaw cycles, and remaining drug concentrations were determined. The results were expressed as the percentage of mean deviation over actual concentrations.

\section{Recovery}

The matrix effect, extraction recovery and process efficiency were evaluated for topotecan and the internal standard $(80 \mathrm{ng} /$ $\mathrm{mL}$ for topotecan and $25 \mathrm{ng} / \mathrm{ml}$ for internal standard, $\mathrm{n}=3$ each). The matrix effect was evaluated by comparing the peak areas between the QC and internal standard solutions added to the extracted blank serum and the QC and internal standard solutions prepared in mobile phase. The extraction recovery 
was evaluated by comparing the peak areas between the extracted QC samples and the extracted blank serum added with the QC and internal standard solutions. The process efficiency was evaluated by comparing the peak areas between extracted QC samples and standard samples prepared in mobile phase.

\section{Application}

Male Sprague-Dawley rats (8-10 weeks old, body weight $257 \pm 26$ g) (Hyochang Science, Daegu, Korea) were kept in plastic cages with free access to standard rat diet (Samyang, Seoul, Korea) and water. The animals were maintained at a temperature of $22-24^{\circ} \mathrm{C}$ with a $12 \mathrm{~h}$ light-dark cycle and relative humidity of $50 \pm 10 \%$. The rats were anaesthetized by i.p. injection of zoletil $50(20 \mathrm{mg} / \mathrm{kg})$ (Virbac, Carros, France) and cannulated with polyethylene tubing $(0.58 \mathrm{~mm}$ i.d., $0.96 \mathrm{~mm}$ o.d, Natsume, Tokyo, Japan) in the right jugular and femoral veins. After a 2-day recovery, topotecan dissolved in a mixture of PEG 400: $\mathrm{KH}_{2} \mathrm{PO}_{4}(\mathrm{pH} 3)(1: 3 \mathrm{v} / \mathrm{v})$ was i.v. injected at a dose of $5 \mathrm{mg} / \mathrm{kg}$ into the femoral vein $(\mathrm{n}=4)$. Venous blood samples $(0.3 \mathrm{~mL}$ each) were collected in eppendorf tubes prior to and 5, 10, 15, $30 \mathrm{~min}, 1,2,4,6,12$ and $24 \mathrm{~h}$ after injection, and the same volumes of saline were replaced. Serum samples were harvested by centrifugation at $1,500 \mathrm{~g}$ for $10 \mathrm{~min}$ and stored at $-20^{\circ} \mathrm{C}$ until analysis. The serum concentration-time data were analyzed by a non-compartmental method using the nonlinear least-squares regression program WinNonlin (Pharsight, Mountain View, CA, USA).

\section{Results and Discussion}

\section{Mass Spectrometry and Chromatography}

A rapid and sensitive LC/MS/MS assay was developed for the determination of topotecan levels in rat serum. Serum samples were processed by a simple liquid-liquid extraction, and the assay was validated over the linear concentration range from $0.5-100 \mathrm{ng} / \mathrm{mL}$. The positive Q1 mass spectrum of topotecan and product ion mass spectrum of protonated topotecan $(\mathrm{m} / \mathrm{z}=422.0)$ are shown in Fig. 1. In the full scan Q1 mass spectrum, the most abundant $[\mathrm{M}+\mathrm{H}]^{+}$was found at $\mathrm{m} / \mathrm{z}=$ 422.0, while other adduct peaks including sodium adduct $[\mathrm{M}+\mathrm{Na}]^{+}$were not detected. The most abundant ion in the product ion scan of topotecan was found at $\mathrm{m} / \mathrm{z}=376.5$. Fig. 2 shows the positive Q1 mass spectrum of clomipramine and the product ion mass spectrum of protonated clomipramine $(\mathrm{m} /$ $\mathrm{z}=315.1$ ). The $\mathrm{Q} 1$ mass spectrum was dominated by the protonated molecular ion $[\mathrm{M}+\mathrm{H}]^{+}$at $\mathrm{m} / \mathrm{z}=314.6$ and the most prominent product ion of the protonated clomipramine was
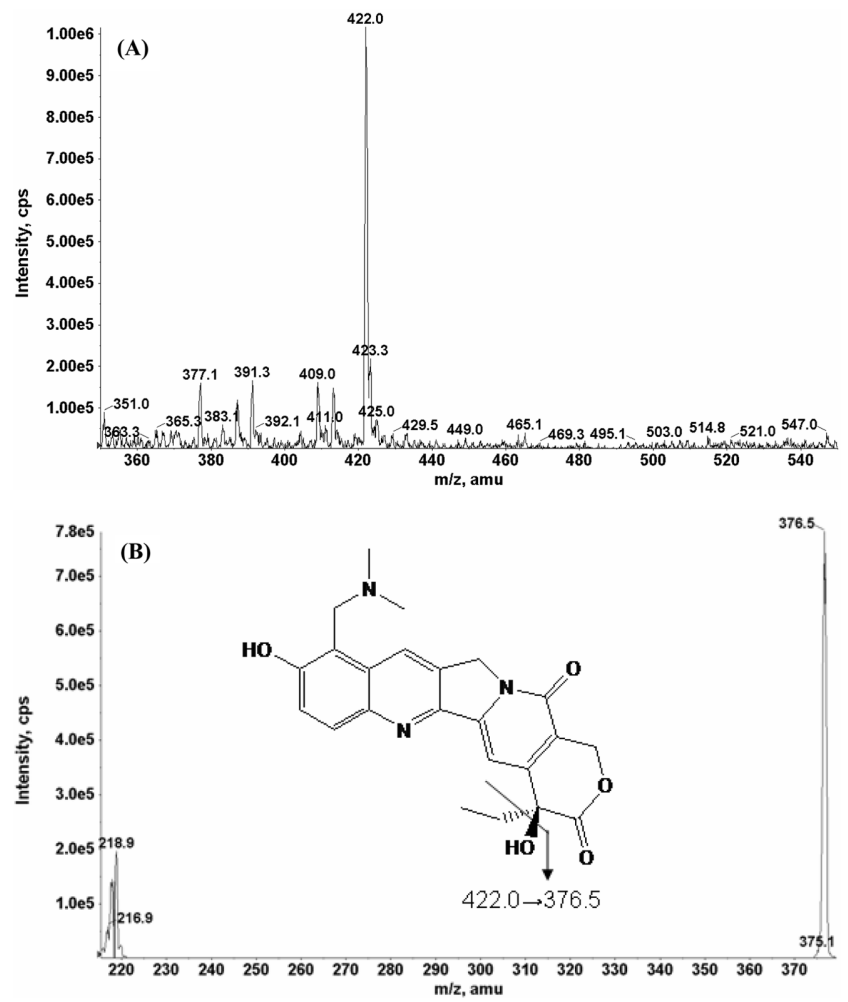

Figure 1-(A) Positive ion Q1 mass spectrum of topotecan and (B) product ion mass of protonated topotecan $\left([\mathrm{M}+\mathrm{H}]^{+}, \mathrm{m} / \mathrm{z} 422.0\right)$.
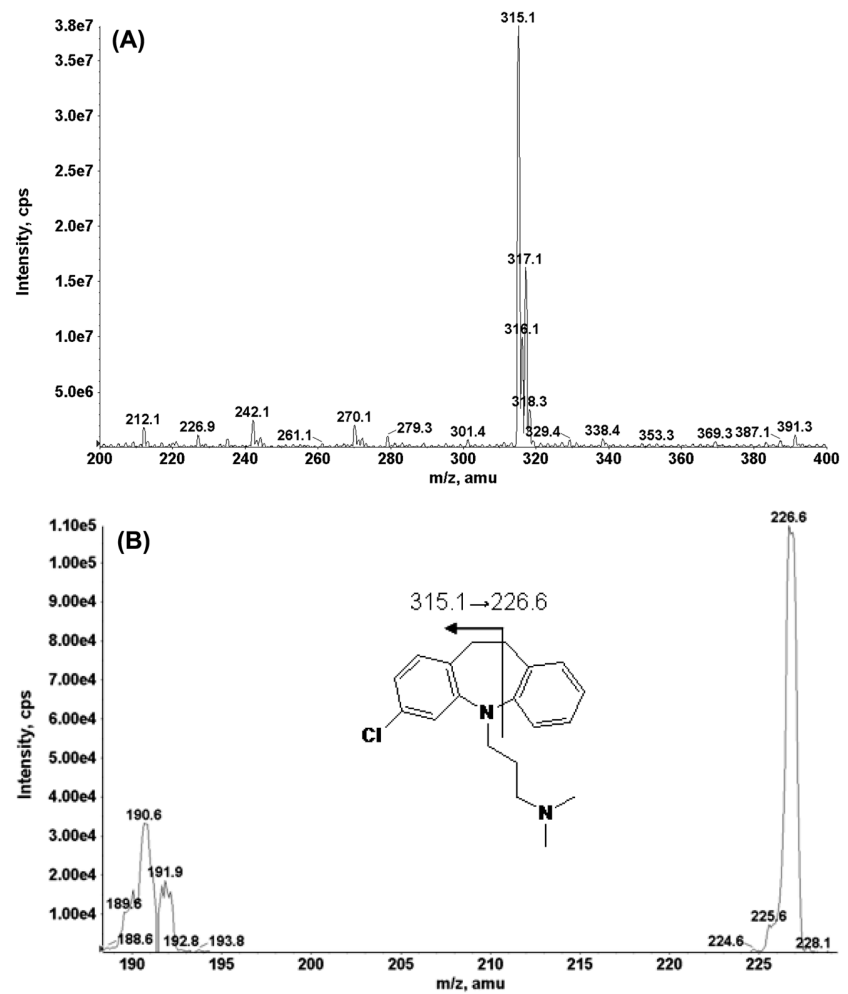

Figure 2-(A) Positive ion Q1 mass spectrum of clomipramine and (B) product ion mass of protonated clomipramine $\left([\mathrm{M}+\mathrm{H}]^{+}, \mathrm{m} / \mathrm{z} 315.1\right)$. 


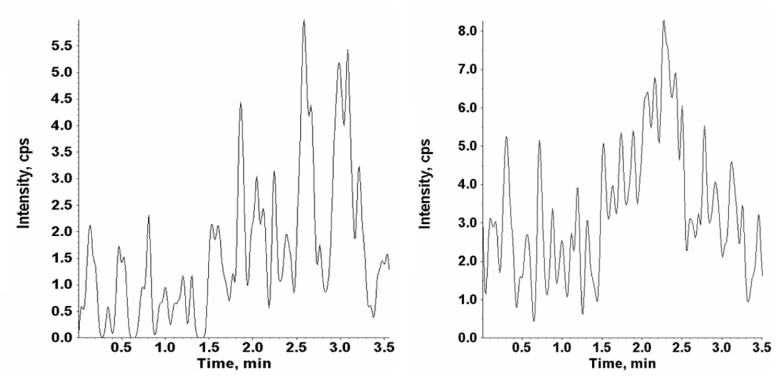

(A)
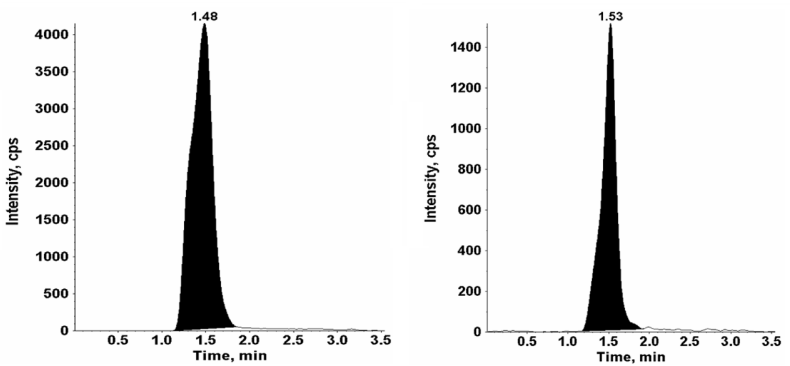

(C)
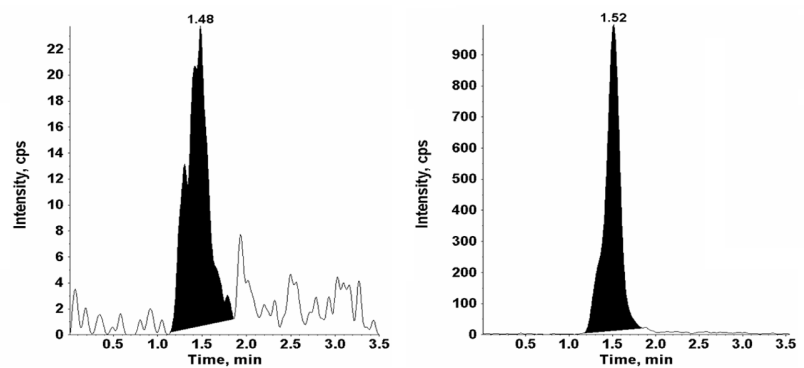

(B)
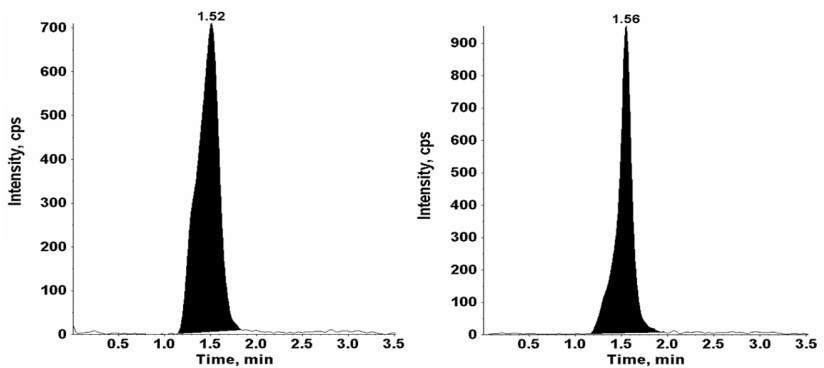

(D)

Figure 3-MRM chromatograms of topotecan (left) at $422.0 \rightarrow 367.5$ and clomipramine (right) at $315.1 \rightarrow 226.6$ obtained by extraction of (A) blank rat serum, (B) serum spiked with topotecan $(0.5 \mathrm{ng} / \mathrm{mL})$ and clomipramine $(25 \mathrm{ng} / \mathrm{mL})$, (C) serum spiked with topotecan $(100$ $\mathrm{ng} / \mathrm{mL})$ and clomipramine $(25 \mathrm{ng} / \mathrm{mL})$, and (D) serum obtained $2 \mathrm{hr}(20.1 \mathrm{ng} / \mathrm{mL})$ after i.v. injection of topotecan to rat $(5 \mathrm{mg} / \mathrm{kg})$.

found at $\mathrm{m} / \mathrm{z}=226.6$. The mass transition was monitored at $422.0 \rightarrow 376.5$ for topotecan and $315.1 \rightarrow 226.6$ for clomipramine, and the optimum MS/MS parameters were selected for the assay. The MRM chromatograms of topotecan and clomipramine obtained by extraction of rat serum are shown in Fig. 3. Topotecan and clomipramine were eluted at 1.4 and 1.5 min, respectively, and the total assay run time was $\leq 3 \mathrm{~min}$, allowing for improved sample throughput times over other assay methods reported previously ${ }^{17-20)}$. Without adjustment of the mobile phase $\mathrm{pH}$, the shape of topotecan peaks was broad. Under the acidic mobile phase condition ( $0.1 \%$ formic acid), a suitable peak shape was obtained, and no endogenous or extraneous peaks interfered with the analytes.

\section{Method Validation}

The assay was linear over the concentration range from 0.5 $100 \mathrm{ng} / \mathrm{mL}$, with a typical correlation coefficient $\geq 0.999$. The LLOQ of this assay was $0.5 \mathrm{ng} / \mathrm{mL}$, using $0.1 \mathrm{~mL}$ of rat serum. The intra- and inter-day accuracy and precision determined at $0.5,8,20$ and $80 \mathrm{ng} / \mathrm{mL}$ are shown in Table 1 . The intra- and inter-day accuracy ranged from $87.7-111.0 \%$ and $97.8-108.3 \%$, respectively, with $\% \mathrm{CV}$ less than $4.3 \%$ and $10.3 \%$, respectively. Results of the auto sampler stability $(24 \mathrm{~h})$, freeze-thaw stability (3 cycles) and short-term stability in serum ( $6 \mathrm{~h}$ at RT) are shown in Table 2 . The absolute mean percentages of devi-
Table I-Average intra- and inter-day Accuracy (mean $\pm S D$ ) and Precision of Topotecan Assay in rat serum

\begin{tabular}{|c|c|c|c|c|}
\hline \multirow{2}{*}{$\begin{array}{c}\text { Topotecan } \\
\text { conc. } \\
(\mathrm{ng} / \mathrm{mL})\end{array}$} & \multicolumn{2}{|c|}{ Intra-day $(n=3)$} & \multicolumn{2}{|c|}{ Inter-day $(n=3)$} \\
\hline & $\begin{array}{c}\text { Accuracy } \\
(\%)\end{array}$ & $\begin{array}{l}\text { Precision } \\
(\%)\end{array}$ & $\begin{array}{c}\text { Accuracy } \\
(\%)\end{array}$ & $\begin{array}{c}\text { Precision } \\
(\%)\end{array}$ \\
\hline 0.5 & $87.7 \pm 3.8$ & 4.3 & $104.4 \pm 10.7$ & 10.3 \\
\hline 8 & $106.3 \pm 2.1$ & 2.0 & $102.8 \pm 5.3$ & 5.2 \\
\hline 20 & $111.0 \pm 2.6$ & 2.4 & $108.3 \pm 4.2$ & 3.8 \\
\hline 80 & $88.2 \pm 1.4$ & 1.6 & $97.8 \pm 5.4$ & 5.6 \\
\hline
\end{tabular}

\section{Table II-Stability of Topotecan}

\begin{tabular}{cccc}
\hline \hline \multirow{2}{*}{$\begin{array}{c}\text { Topotecan } \\
\text { Conc. (ng/mL) }\end{array}$} & \multicolumn{3}{c}{ Deviation of mean from theoretical (\%) } \\
\cline { 2 - 4 } & $\begin{array}{c}\text { Auto sampler } \\
(24 \mathrm{~h})\end{array}$ & $\begin{array}{c}\text { Freeze-thaw (3 } \\
\text { cycles) }\end{array}$ & $\begin{array}{c}\text { Serum at RT (6 } \\
\text { h) }\end{array}$ \\
\hline 8 & -7.9 & 9.4 & -9.3 \\
80 & 4.3 & 4.8 & -4.8 \\
\hline
\end{tabular}

ation of calculated vs. theoretical concentrations were $\leq 7.9 \%$ for auto sampler stability, $\leq 9.4 \%$ for freeze-thaw stability and $\leq 9.3 \%$ for short-term stability in serum. The extraction recoveries determined at high QC concentrations were 68.0 $\pm 5.7 \%$ for topotecan and $58.9 \pm 3.4 \%$ for the internal standard. The extraction recovery was not high, probably due to the hydrophilic proprieties of topotecan. Nevertheless, the variance was 
Table 3-Recovery, Matrix Effect and Process Efficiency of Topotecan (mean $\pm S D$ )

\begin{tabular}{cccccc}
\hline \hline \multicolumn{2}{c}{ Recovery (\%) } & \multicolumn{2}{c}{ Matrix effect (\%) } & \multicolumn{2}{c}{ Process efficiency (\%) } \\
\hline Analyte & I.S. & Analyte & I.S. & Analyte & I.S. \\
$68.0 \pm 5.7$ & $58.9 \pm 3.4$ & $90.6 \pm 4.5$ & $79.4 \pm 5.8$ & $61.5 \pm 4.2$ & $46.7 \pm 4.2$
\end{tabular}

relatively low $(8.3 \%$ for topotecan and $5.8 \%$ for internal standard). To optimize the extraction recovery, various solvents including $t$-butyl methyl ether, pentane and ethyl acetate were examined. The extraction recovery was low $(<10 \%)$ for pentane and $t$-butyl methyl ether. The highest efficiency was obtained for the ethyl acetate and acetonitrile mixture $(6: 1, \mathrm{v} /$ v). It is possible that co-eluting endogenous components may affect the signal via suppression of the ESI efficiency of analytes. In this assay, the retention times of topotecan and internal standard were less $2 \mathrm{~min}$, resulting in high suppression of ESI due to co-elution of endogenous interference. The matrix effect appears acceptable for topotecan $(90.6 \pm 4.5 \%)$ and the internal standard $(79.4 \pm 5.8 \%)$, with relatively low variance. It is possible that the liquid-liquid extraction used in this assay may have effectively removed co-eluting endogenous components, resulting in insignificant matrix effects for the analytes. The overall process efficiency was $61.5 \pm 4.2 \%$ for topotecan and $46.7 \pm 4.2 \%$ for the internal standard.

\section{Application}

The developed LC/MS/MS assay was applied to a pharmacokinetic study in rats after i.v. injection of topotecan at a dose of $5 \mathrm{mg} / \mathrm{kg}$. The LLOQ of the assay was sufficient to

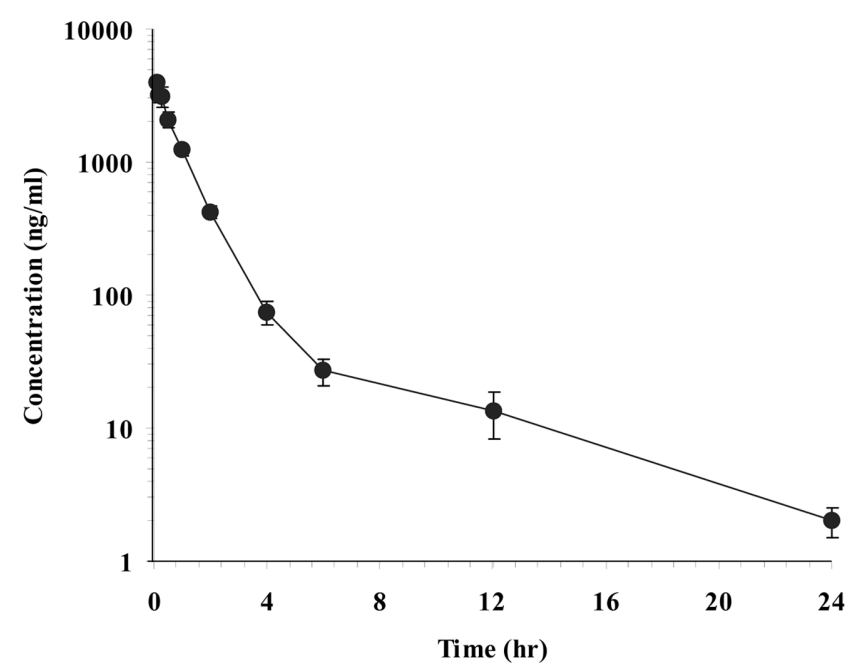

Figure 4-Average serum concentration-time curves (mean \pm SD) obtained in rats after intravenous injection administration of topotecan $(5 \mathrm{mg} / \mathrm{kg}, \mathrm{n}=4)$.
Table 4-Pharmacokinetic Parameters of Topotecan in rats $(n=$ 4) obtained after i.v. injection at a dose of $5 \mathrm{mg} / \mathrm{kg}$

\begin{tabular}{cc}
\hline \hline Parameters & Mean \pm S.D. \\
\hline $\mathrm{t}_{1 / 2}(\mathrm{hr})$ & $4.6 \pm 0.4$ \\
$\mathrm{AUC}_{\mathrm{all}}(\mathrm{ng} \cdot \mathrm{hr} / \mathrm{mL})$ & $4029 \pm 224$ \\
$\mathrm{AUC}_{\mathrm{inf}}(\mathrm{ng} \cdot \mathrm{hr} / \mathrm{mL})$ & $4060 \pm 250$ \\
$\mathrm{Cl}_{\mathrm{s}}(\mathrm{mL} / \mathrm{min})$ & $20.6 \pm 1.3$ \\
$\mathrm{~V}_{\mathrm{ss}}(\mathrm{L} / \mathrm{kg})$ & $1.9 \pm 0.1$ \\
\hline
\end{tabular}

characterize the pharmacokinetics of topotecan. The mean concentration of topotecan vs. time profile is shown in Fig. 4. Pharmacokinetic parameters of topotecan are summarized in Table 4. The terminal elimination half-life $\left(t_{1 / 2}, 1 z\right)$, systemic clearance $\left(\mathrm{Cl}_{\mathrm{s}}\right)$, and steady-state volume of distribution $\left(\mathrm{V}_{\mathrm{ss}}\right)$ were $4.6 \pm 0.4 \mathrm{~h}, 20.6 \pm 1.3 \mathrm{~mL} / \mathrm{min} / \mathrm{kg}$, and $1.9 \pm 0.1 \mathrm{~L} / \mathrm{kg}$, respectively.

\section{Conclusions}

A rapid and sensitive LC/MS/MS assay was developed for the determination of topotecan levels in rat serum. The assay showed a linear dynamic range from $0.5-100 \mathrm{ng} / \mathrm{mL}$, with acceptable intra- and inter-day accuracy and precision. The developed assay was applied to a pharmacokinetic study in rats after i.v. injection of topotecan $(5 \mathrm{mg} / \mathrm{kg}$ dose).

\section{Acknowledgements}

This research was supported by research grants from Catholic University of Daegu in 2008.

\section{References}

1) D. Costin and M. Potmesil, Preclinical and clinical development of camptothecins, Adv. Pharmacol., 29B, 51-72 (1994).

2) G.J. Creemers, B. Lund, J. Verweij, Topoisomerase I inhibitors: topotecan and irinotecan, Cancer Treat. Rev, 20, 73-96 (1994).

3) C.J. Gerrits, M.J. de Jonge, J.H. Schellens, G. Stoter and J. Verweij, Topoisomerase I inhibitors: the relevance of prolonged exposure for present clinical development, Br. J. Cancer, 76, 952-962 (1997).

4) V.M. Herben, W.W. ten Bokkel Huinink and J.H. Beijnen, Clinical pharmacokinetics of topotecan, Clin. Pharmacokinet., 31, 85-102 (1996).

5) R.K. Johnson, R.P. Hertzberg, W.D. Kingsbury, J.C. Boehm, M.J. Caranfa, L.F., Faucette, F. L. McCabe and K.G. Holden, Proceeding of the sixth NCIEORTC symposium on new drugs in cancer therapy, 301 (1989).

6) W.D. Kingsbury, J.C. Boehm, D.R. Jakas, K.G. Holden, S.M. Hecht, G. Gallagher, M.J. Caranfa, F.L. McCabe, L.F. Faucette 
and R.K. Johnson, Synthesis of water-soluble (aminoalkyl)camptothecin analogues: inhibition of topoisomerase I and antitumor activity, J. Med. Chem., 34, 98-107 (1991).

7) H.A. Burris 3rd, A.R. Hanauske, R.K. Johnson, M.H. Marshall, J.G. Kuhn, S.G. Hilsenbeck and D.D. Von Hoff, Activity of topotecan, a new topoisomerase I inhibitor, against human tumor colony-forming units in vitro, J. Natl. Cancer Inst., 84, 1816-1820 (1992).

8) S.C. Plaxe, R.D. Christen, J. O'Quigley, P.S. Braly, J.L. Freddo, E. McClay, D. Heath and S.B. Howell, Phase I and pharmacokinetic study of intraperitoneal topotecan, Invest. New Drugs, 16, 147-153 (1998).

9) L.S. Hofstra, A.M. Bos, E.G. de Vries, A.G. van der Zee, J.H. Beijnen, H. Rosing, H.N. Mulder, J.G. Aalders and P.H. Willemse, A phase I and pharmacokinetic study of intraperitoneal topotecan, Br. J. Cancer., 85, 1627-1633 (2001).

10) R.P. Hertzberg, M.J. Caranfa, K.G. Holden, D.R. Jakas, G. Gallagher, M.R. Mattern, S.M. Mong, J.O. Bartus, R.K. Johnson and W.D. Kingsbury, Modification of the hydroxy lactone ring of camptothecin: inhibition of mammalian topoisomerase I and biological activity, J. Med. Chem., 32, 715-720 (1989).

11) C.F. Stewart, W.C. Zamboni, W.R. Crom, A. Gajjar, R.L. Heideman, W.L. Furman, W.H. Meyer, P.J. Houghton and C.B. Pratt, Topoisomerase I interactive drugs in children with cancer, Invest. New Drug, 14, 37-47 (1996).

12) T. Yamagata and H. Kusuhara, M. Morishita, K. Takayama, H. Benameur, Y. Sugiyama, Improvement of the oral drug absorption of topotecan through the inhibition of intestinal xenobiotic efflux transporter, breast cancer resistance protein, by excipients, Drug Metab. Dispos., 35, 1142-1148 (2007).

13) J. Shen, A.M. Carcaboso, K.E. Hubbard, M. Tagen, H.G. Wynn, J.C. Panetta, C.M. Waters, M.A. Elmeliegy and C.F. Stewart, Compartment-specific roles of ATP-binding cassette transporters define differential topotecan distribution in brain parenchyma and cerebrospinal fluid, Cancer Res., 69, 58855892 (2009).
14) Y. Su, P. Hu , S.H. Lee and P.J. Sinko, Using novobiocin as a specific inhibitor of breast cancer resistant protein to assess the role of transporter in the absorption and disposition of topotecan, J. Pharm. Pharm. Sci., 10, 519-36 (2007).

15) N.A. de Vries, J. Zhao, E. Kroon, T. Buckle, J.H. Beijnen and $\mathrm{O}$. van Tellingen, P-glycoprotein and breast cancer resistance protein: two dominant transporters working together in limiting the brain penetration of topotecan, Clin. Cancer Res., 13, 6440-6449 (2007).

16) S. Zhang, X. Wang, K. Sagawa and M.E. Morris, Flavonoids chrysin and benzoflavone, potent breast cancer resistance protein inhibitors, have no significant effect on topotecan pharmacokinetics in rats or mdrla/lb (-/-) mice, Drug Metab. Dispos., 33, 341-348 (2005).

17) J.H. Beijnen, B.R. Smith, W.J. Keijer, R. van Gijn, W.W. ten Bokkel Huinink, L.T. Vlasveld, S. Rodenhuis and W.J. Underberg, High-performance liquid chromatographic analysis of the new antitumor drug SK\&F 104864-A (NSC 609699) in plasma, J. Pharm. Biomed. Anal., 8, $789-794$ (1990).

18) W.J. Loos, G. Stoter, J. Verweij and J.H. Schellens, Sensitive high-performance liquid chromatographic fluorescence assay for the quantitation of topotecan (SKF 104864-A) and its lactone ring-opened product (hydroxy acid) in human plasma and urine, J. Chromatogr. B Biomed. Appl., 678, 309-315 (1996).

19) H. Rosing, D.M. van Zomeren, E. Doyle, W.W. ten Bokkel, J.H. Schellens, A. Bult and J.H. Beijnen, Quantification of topotecan and its metabolite N-desmethyltopotecan in human plasma, urine and faeces by high-performance liquid chromatographic methods, J. Chromatogr. B Biomed. Sci. Appl., 727, 191-203 (1999).

20) J. Chen and J.P. Balthasar, High-performance liquid chromatographic assay for the determination of total and free topotecan in the presence and absence of anti-topotecan antibodies in mouse plasma, J. Chromatogr. B Analyt. Technol. Biomed. Life Sci., 816, 183-192 (2005). 